\title{
Directions and Prospects of Integrated Innovative Development of the Transport Infrastructure of the Russian Federation
}

\author{
Irina Misanova ${ }^{1,2, *}$, Maksim Filippov ${ }^{2}$, Dmitry $_{\text {Tarasov }}{ }^{3}$, Veronika Viushkova $^{2}$, and \\ Elizaveta Zhukova ${ }^{2}$ \\ ${ }^{1}$ I.M. Gubkin Russian State University of Oil and Gas, 119991 Moscow, Russia \\ ${ }^{2}$ Russian University of Transport, 127994 Moscow, Russia \\ ${ }^{3}$ Financial University under the Government of the Russian Federation, 125993 Moscow, Russia
}

\begin{abstract}
As an economic development determinant, transport needs to be improved on an ongoing basis. This is due to complex dynamic processes taking place both within the state and internationally. Social and economic transformations and scientific progress of the 21 st century in the national economic sectors challenge the national policy of any state. The readiness for macroeconomic turbulence and the level of adaptability depend, to a decisive extent, on the economic potential of the state, where transport is the connecting link between the production, research and technical, agricultural and social components. As a backbone industry, the transport complex is based on infrastructure. The development of transport infrastructure is fundamental and is considered a priority not only at the national level, but also within the framework of globalization processes. Thus, the importance of resolving the issues of transport infrastructure development is due to the rapid development of the national economy as a whole. In this regard, the article emphasizes the importance of the integrated innovative development of Russia's transport complex infrastructure and reveals promising directions for its development in conditions of market constraints.
\end{abstract}

\section{Introduction}

Currently, the content of the implementation of large infrastructure transport projects is inseparable from such definitions as infrastructure, its functionality in the development of the national economy, infrastructural limitations and the ability to overcome them.

Communication and service systems are important infrastructure components today. The components of the service system are: utilities, trade, food industry, education, health care, culture, institutions of state and social security, financial and credit system. The components of the communication system include transport, communications, information technology [1].

\footnotetext{
*Corresponding author: kino-rodina@,mail.ru
} 
Infrastructure is of great importance for the development of states: its availability serves as a prerequisite for the implementation of many capabilities in all spheres of human life.

The quality of infrastructure development refers to the basic factor affecting a state's rank according to theGCI ("Global Competitiveness Index"), calculated by WEF ("World Economic Forum") [2, 3].

According to the WEF, Russia in 2019 ranked 43rd among 141 countries according to the GCI index, taking 50th place in the quality of transport infrastructure development. The five leaders include countries with highly developed transport communications: Singapore, USA, Hong Kong, Netherlands, Switzerland. China is the leader among the BRICS countries, ranking 28th according to the GCI index [3].

For Russia, the development of transport infrastructure is of strategic importance: its condition allows the state to solve the problems of social and economic growth, ensure territorial integrity, and create instruments of influence on global economic processes. President of the Russian Federation V.V. Putin in his Address to the Federal Assembly noted that "for the growth of business activity, ensuring the "connectedness" of the country, it is necessary to literally "upgrade" the entire territory of Russia with modern communications" [4].

The prerequisites for the need for the development of transport communications are to create transport conditions to achieve the following capabilities:

- Economic acculturation of areas of production and consumption.

- Regional production specialization by organizing new ways of exchange of goods and creating new production facilities, as well as demonopolizing local producers.

- Improving the quality of all aspects of life of the population, increasing its geographic mobility [5-8].

The balanced development of the infrastructure of the transport complex provides conditions for the growth of the national economy, while unbalanced infrastructural development can cause its limitations.

It should be noted that transport is still not sufficiently adapted to market relations. For instance, despite the fact that the operators of transport infrastructure are private companies, most of the infrastructure facilities are in the scope of the direct responsibility of the state and require its systemic support [9].

According to experts, the solution of existing infrastructure problems is possible in an innovative way, which provides for the implementation of large infrastructure transport projects, mainly state/private partnerships, which are inherently innovative, since they are focused on the output of a unique product, using innovations in technology and management in the process of its creation. [9-12].

\section{Materials and methods}

The content of the implementation of large infrastructure transport projects is determined by a set of interrelated documents, including:

- Forecast of social and economic development of the Russian Federation up to 2024.

- Transport strategy up to 2030.

- State program "Transport System Development".

- Comprehensive plan for the update and expansion of the backbone infrastructure up to 2024 [12].

- Federal target-oriented and regional programs.

- Strategies and concepts for the development of all types of transport [12, 13].

The Forecast of social and economic development approved national priorities for modifying transport infrastructure: 
- Transformation of the backbone network in order to increase the speed of transportation.

- Reconstruction of transport corridors and the Northern Sea Route.

- Updating the infrastructure of inland water transport, seaports and airports [12, 14].

In connection with national priorities, the updated Transport Strategy defines national goals for the development of transport infrastructure:

- Achieving transport connectivity between the capital and regions.

- Achieving containerization of freight transport.

- Achieving quality of the passenger transport service.

- Achieving mutual integration of Russian and global transport systems.

- Achieving maximum safety of the transport complex [12].

\section{Results and discussion}

According to the Transport Strategy, two scenarios of infrastructural development are possible: baseline (conservative) and innovative [12].

While implementing the first option, measures to develop the infrastructure of the transport complex of Russia will be carried out, first of all, in metropolitan agglomerations and in regions with high growth rates [12]. However, no radical improvement in transport links between the regions and the capital is predicted. The implementation of the baseline scenario will be accompanied by a low growth rate of population mobility, which will negatively affect, first of all, the volume of passenger transport. However, an imbalance will remain in ensuring the availability of transport services in the regions and for social groups. Insufficient investment activity will lead to budget financing of construction, repair and maintenance of infrastructure facilities $[6,12]$. The innovative scenario provides for the implementation of large infrastructure transport projects throughout the country with a high degree of innovation, which will provide incentives for the high-tech manufacturing sector [12]. The implementation of this option will ensure the development of the innovative potential of the national economy, improving the quality of life of the population, and the transition to a polycentric model of the spatial development of territories $[6,12,15]$.

To achieve the strategic goals of transport development, the Comprehensive Plan includes the following program plans covering the development of all types of transport, aimed at eliminating bottlenecks in the transport complex of the Russian Federation [16]:

- Development of national infrastructure of international importance, including transport corridors.

- Building of highways, including those of international importance.

- Increase in the volume of transit container transport by rail.

- Updating the Baikal-Amur and Trans-Siberian railway lines and increasing their carrying capacity up to 180 million tons.

- Updating the infrastructure of seaports; expansion of the Northern Sea Route to achieve freight transport up to 80 million tons.

- Updating the infrastructure of regional airports

- Creation of multimodal transport and logistics centers.

- Development and update of transport communications between the centers of economic growth [12].

Based on the foregoing, the following components of the implementation of large infrastructure transport projects can be distinguished, demonstrating an integrated innovative approach to the development of transport infrastructure:

1. Forecast of social and economic development of the country, taking into account:

- Implementing the goal setting of the Transport Strategy. 
- Implementing the Infrastructure Renovation Comprehensive Plan.

- Implementing the program for the development of modes of transport [12].

2. Supporting national priorities for the development of transport infrastructure, taking into account:

- National goals for the development of transport infrastructure.

- Plans for the development of transport infrastructure.

- Measures for the development of modes of transport [12].

3. Active introduction of innovations, information and digital technologies as an effective toolkit for the functioning and development of the transport complex of the Russian Federation.

This approach allows for the classification of transport infrastructure projects according to their degree of national importance, setting a new vector of the content of the implementation of large infrastructure transport projects, specifically: the activities planned for implementation are lined up in a single "chain".

\section{Conclusions}

1. Thus, it is impossible to effectively solve the systemic problems of transport infrastructure without applying an innovative approach to technologies and without attracting investments [17].

2. The content of large infrastructure transport projects forms an innovative component of the state transport strategy, and their implementation requires state investment.

3. Large infrastructure transport projects should be considered as a substantial part of the country's national projects in general. In the period of macroeconomic instability, their implementation will allow overcoming the existing restrictions on the development of the Russian economy.

\section{References}

1. S.V. Rachek, N.F. Sirina, Y.V. Khomenko, I.N. Kolesnikov, 3rd International Scientific and Practical Conference (DEFIN 2020), 19-20 March 2020, Saint Petersburg, Russia, 3390812 (2020)

2. K. Schwab, The Global Competitiveness Report 2019 (2019)

3. S. Park, Transport Policy, 99, 54 (2020)

4. I.D. Matskulyak, W.-T. Veila, T.N. Kleshchinskaya, D.I. Matskulyak, I.N. Misanova, N.Z.-O. Nagdaliev, Yu.B. Prutin, Z.I. Skvortsova, B.G. Ubushaeva, O.V. Shinkareva, Financial Economics, 1, 7 (2018)

5. C. Ferrari, A. Bottasso, M. Conti, A. Tei, Economic Role of Transport Infrastructure: Theory and Models (2019)

6. D.A. Macheret, A.Yu. Ledney, Transport of the Russian Federation, 5, 16 (2018)

7. C. Baldwin, B. Lewis, P. Greenwood, Designing Transportation Systems for Older Adults (2019)

8. O. Skorobogatova, I. Kuzmina-Merlino, 16th Conference on Reliability and Statistics in Transportation and Communication (RelStat 2016), 19-22 October, 2016, Riga, Latvia, 178, 319 (2016) 
9. I.N. Misanova, State Regulation of Economy: Political and Economic Aspects (5th International Scientific and Practical Conference), December 8, 2017, Moscow, Russia, 18 (2018)

10. V.I. Yakunin, Political Science, S, 15 (2017)

11. I.V. Mitrofanova, A.B. Tlisov, A.N. Zhukov, L.M. Shavtikova, Bulletin of Volgograd State University, Economics, Ecology, 3, 107 (2016)

12. A.S. Misharin, O.V. Evseev, Transport of the Russian Federation, 2, 4 (2013)

13. D.E. Tarasov, K.N. Rusanovskaya (Bugai), L.A. Mamykin, Economic and SocioHumanitarian Studies, 3, 34 (2020)

14. I. Shevchenko, V. Ponomarev, M. Ponomareva, N. Kryuchenko, Lecture Notes in Networks and Systems, 78, 374 (2020)

15. N.D. Berman, International J. of Advanced Studies, 2, 7 (2020)

16. D.A. Macheret, A.Yu. Ledney, Economics of Railways, 1, 31 (2019)

17. V.S. Myasnikov, Modern Aspects of Economics, 1, 6 (2020) 